\title{
The development of interaction skills in preservice teacher education: A mixed-methods study of Dutch pre-service teachers
}

\author{
Ruben Fukkink $^{1}$ (D) Lisanne Jilink ${ }^{1} \cdot$ Rosanne Op den Kelder $^{1} \cdot$ Kirti Zeijlmans $^{2} \cdot$ Iris Bollen $^{3} \cdot$ Letty Koopman $^{1}$
}

Published online: 12 February 2019

(C) The Author(s) 2019

\begin{abstract}
Significant attention has been paid in the international literature to the effect of in-service training on the interaction skills of teachers in early childhood education and care. The growth of pre-service teachers during teacher education has received relatively little attention to date, however. In a mixed-methods longitudinal study, we monitored the development of interaction skills among a group of Dutch pre-service teachers with repeated measures for 3 years and structured interviews. The results of a linear mixed-effects model revealed an impressive growth of interaction skills during the pre-service training. The qualitative interview data revealed progress of pre-service teachers' professional reflection on their interaction with young children. These outcomes show the effectiveness of pre-service training for the development of interaction skills and professional reflection in early childhood education and care. However, progress is relatively modest for instructional skills and this domain needs further investment in pre-service training.
\end{abstract}

Keywords Interaction skills $\cdot$ Early childhood education and care $\cdot$ Pre-service training $\cdot$ Longitudinal study $\cdot$ Mixedmethods

Professional development (PD) of teachers working in early childhood education and care (ECEC) is high on the educational agenda in many countries. Different countries invest in pre- and in-service training for early childhood teachers to improve quality of child care and to foster the development of young children in ECEC (Sumrall et al. 2017; Urban et al. 2012). This policy of investing in the PD of staff is supported by a growing body of evidence that training of teachers is a cornerstone for quality in ECEC. Early childhood teachers with higher levels of training are more often engaged in sensitive and stimulating interactions with children; they provide more sensitive care, are more involved with children, and offer richer learning experiences (Werner

Ruben Fukkink

R.G.Fukkink@uva.nl

1 University of Amsterdam, Research Institute of Child Development and Education, P.O. Box 15776, 1001 NG Amsterdam, the Netherlands

2 Department of Special Needs Education and Youth Care, University of Groningen, Grote Rozenstraat 38, 9712 TJ Groningen, the Netherlands

3 Kohnstamm Instituut, Postbus 94208, 1090 GE Amsterdam, the Netherlands et al. 2016; Fukkink and Lont 2007). In addition, a recent meta-analysis showed that investing in the PD of staff and process quality of ECEC is also positively related to the development of young children (Egert et al. 2018).

Over the past few years, there has been a significant increase in experimental research into the PD and the effects of in-service training related to teachers' interaction skills. These studies have demonstrated that specialised training can improve the pedagogical quality of interactions between teachers and children (Werner et al. 2016; Helmerhorst et al. 2017). However, less attention has gone to the development of important professional competencies in pre-service training. This topic is important because high-quality caregiverchild interactions of ECEC staff, including both newly qualified and experienced teachers, constitute the core of high-quality child care for young children. Further, preservice training is assumed to ensure that practitioners have the competencies needed to support the development and learning of young children, laying a foundation for teachers' PD (Hamre 2014; Institute of Medicine and National Research Council 2015). In recent studies, surveys have been used to investigate prospective ECEC teachers' self-esteem (e.g., Mischo 2015), teacher beliefs (e.g., Vartuli and Rohs 2009), self-efficacy (e.g., Guo et al. 2010), and self-reported 
perceptions of their professional competence (e.g., Mischo 2015; Strohmer and Mischo 2016). Observational studies of prospective teachers are needed, however, to provide direct insight into pre-service teachers' interaction skills in ECEC practice. In this study, we monitored the professional growth of pre-service teachers in an observational study to chart the development of interaction skills from the start until the end of their preservice teacher education.

A number of authors have emphasized the need to focus on the learning process and experiences of ECEC teachers during their PD (see Sheridan et al. 2009; Snyder et al. 2012). As Sheridan et al. (2009) emphasize, reflections of ECEC teachers in PD are worthy of systematic study. This line of research may contribute to our limited knowledge of how learning and skill acquisition is accomplished in the ECEC field. Future research should therefore increase our insight into key components of programmes and prospective teachers' personal experiences of change during PD. This paradigm shift involves a double focus on both learning processes and learning outcomes, which requires that studies into the process of PD draw from multiple sources (Schachter 2015), including not only measures to monitor progress of key competencies, but also complementary measures to map practitioners' reflection on key competencies from the curriculum. In the context of preservice teacher education, this paradigm implies that in-depth studies should track prospective ECEC teachers' progress along these two lines, preferably from the start until the end of their training. To our knowledge, no such study has been conducted with prospective ECEC teachers.

Pre-service training for the ECEC sector in the Netherlands is the 3 year senior secondary vocational course in Pedagogical Work (see Fukkink 2018). The national preservice teacher education for childcare has shifted its broad focus on care and welfare in general (e.g., care for children, elderly, people who have disabilities) to one on care for children in 2012, reflecting a change from social care work to pedagogical work. Whereas the former vocational training programme for child care (in Dutch: 'Sociaal Pedagogisch Werk') offered a general curriculum for pre-service workers, the current training is tailored to working with children and has a clearer focus on child care.

Related to the curricular transition, an innovative part of the Dutch curriculum is devoted to explicit training of interaction skills that are relevant for interactions between caregivers and children. The Dutch curriculum distinguishes between six skills: sensitive responsiveness, respect for autonomy, and structuring and limit setting but lower scores for the more educational skills of verbal communication, developmental stimulation, and fostering positive peer interactions (see Helmerhorst et al. 2015). This shift in Dutch teacher training fits in with a global trend for in-service training and pre-service training to train key interaction skills of ECEC staff that are important for the well-being, play and development of young children. Staff-child interaction skills are included in steering documents and curricula of preservice teacher education for ECEC in different European countries and the United States (see Eurydice 2014; NAEYC 2009; Oberhuemer and Schreyer 2018). Interacting with children is also an essential element of work placements which are a regular feature of preservice teacher education (Sumrall et al. 2017).

The Dutch teacher education for ECEC distinguishes between two levels within the training: the basic qualification level (European Qualification Framework, EQF level 3 ) and at a higher level (EQF level 4); both levels are below bachelor level. Furthermore, there is a difference in two learning paths: school-based and on-the-job training. For the school-based students, $60 \%$ of the course is school-based and $40 \%$ is spent in a work placement, while the on-the-job training pathway students spend $20 \%$ of their time at school and $80 \%$ in a work placement. The above mentioned six interaction skills are included in the curriculum of both the school-based and on-the-job pathway. Also work placements begin in the first year for both pathways.

Empirical research into preservice teacher education for ECEC is needed in order to gain a greater insight into the development of interaction skills of future professionals coming into the sector. Our study aims to gain insight into learning outcomes of pre-service ECEC teachers and into the process of teacher development by drawing from multiple sources. In a longitudinal study, we monitored the development of a small cohort of pre-service ECEC teachers, analyzing both external evaluations of their interaction skills and interview data to elucidate the development of pre-service teachers' interaction skills. We studied two central questions:

1. What are the learning outcomes of ECEC pre-service teachers related to their interaction skills during teacher education?

2. How do pre-service early childhood teachers reflect on their interaction skills and the progress made over time?

\section{Method}

\section{Present Study}

\section{Study Design}

The design included four waves of data collection. The first measurement was in the first academic year after pre-service teachers began their work placements, usually around 3 months after the start of the academic year. The second 
measurement occurred at the end of the first year. The third measurement was at the end of the second year, and the fourth measurement was at the end of the third year when pre-service training was completed.

Both quantitative and qualitative data were gathered in this study in a nested mixed-methods design with concurrent data collection (see Creswell et al. 2003). The quantitative data provided insight into pre-service teachers' behaviour in ECEC practice, whereas the qualitative data provided insights into their individual learning experiences. The mixed-methods design of our study allowed us to study PD, taking into account both the growth of interaction skills in ECEC practice (i.e., learning outcomes) and their level of professional reflection (i.e., learning processes, see Measures below), following recommendations from Schachter (2015), Sheridan et al. (2009) and Snyder et al. (2012). The mixed-methods design made it also possible to explore the possible link between pre-service teachers' growth of interaction skills (research question 1) and reflection on their PD (research question 2).

\section{Sample}

A total of 47 pre-service teachers in the Pedagogic Work course at the Regional Training Center of Amsterdam ('ROC van Amsterdam') participated in the study. They were, on average, 23.1 years $(S D=9.7)$ and most were female $(96 \%)$, which is characteristic for the Dutch ECEC workforce. The Netherlands was the country of birth for two-thirds of the participants. The other participants came from Morocco, Suriname and the Antilles, Chile, Egypt, Ghana, the Cape Verde islands, Somalia, and Spain.

Out of the total of 47 pre-service teachers, 17 no longer participated after the second wave of data collection. Six students dropped out over in the next the 2 years period, because they quit the course. The total group of dropouts differed from the remaining pre-service teachers in terms of ethnicity: more native Dutch people dropped out, $\chi^{2}(1)=4.37, p=.037$. There were no significant differences in terms of learning pathway (school-based or on-the-job), $\chi^{2}(1)=0.18, p=.67$; Dutch as native language, $\chi^{2}(1)=1.02$, $p=.31$; preservice teacher education level three or four, $\chi^{2}(1)=.09, p=.76$; age, $F(1,45)=0.10, p=.75$; or having their own children, $\chi^{2}(1)=0.79, p=.37$. The final sample and the attrition group did not show statistically significant differences on the outcome measure, although there was a trend effect of trainees who were still included in the final wave with slightly lower scores at the first wave than the students who dropped out (3.19 vs. 3.56, respectively), $F(1$, 45) $=3.86, p=.056$.

An a priori power analysis with G*POWER (Faul et al. $2007)$ indicated that the initial sample allowed a statistical test of detecting a linear trend with adequate power $(\beta=.80)$ at the conventional alpha level $(\alpha=.05)$ for $f^{2}$ values of 0.18 (corresponding to a $R^{2}$ value of .15). The final sample $(N=23)$ still allowed a statistical test with adequate power for $f^{2}$ values of .33 (corresponding to a $R^{2}$ value of .25). A post-hoc analysis for multilevel repeated measures analysis, using optimal design software (Spybrook et al. 2011), indicated that the statistical power was .90 for the observed effect size from our study ( $E S=1.67$ for the aggregated CIP measure); in fact, statistical power was adequate for effect sizes $\geq 1.00$. Hence, statistical power in our study was adequate for large effect sizes.

\section{Measures}

\section{Caregiver Interaction Profile (CIP)}

A research assistant made two 10 min video recordings of teacher-children interactions from practicum in both a lunch and a structured play situation. The educational materials of each session (e.g., a toy building set or drawing materials) enabled a teacher-driven approach to play and encouraged interaction both between the teacher and the children and among the children themselves. The videotapes of the preservice teachers who were filmed at their work placement locations were evaluated using the CIP instrument for the assessment of interaction skills. These skills were measured on a seven-point scale with the following anchors: $7=$ very high, $6=$ high, $5=$ moderately high, $4=$ moderate, $3=$ mod erately low, $2=$ low, and $1=$ very low. Scores under 3.5 are defined as inadequate, scores between 3.5 and 4.5 as moderate, and scores above 4.5 as adequate to good. Also an aggregate score was calculated (CIP total), averaging the scores for the six skills. A validation study of this instrument showed adequate reliability, convergent validity, discriminant validity and predictive validity (see Helmerhorst et al. 2014 for a full description). In our study, trained observers, who met the criterion of an agreement score of .70 (intraclass correlation, mixed model, absolute agreement), independently assessed the filmed episodes. Assessors of the recordings had not visited the locations, in order to rule out contamination of judgment.

\section{Semi-structured Interviews}

The individual interviews, which lasted about $45 \mathrm{~min}$, included open questions, concerning pre-service teachers' learning experiences during their pre-service training including the work placement. Key questions, which were included at each wave, were related to pre-service teachers' development of the six interaction skills from the Dutch curriculum (e.g., What is difficult when you interact with children from the group? And, what is easy?). We also asked the participants to reflect on their development (e.g., What are the most 
important things you have learned so far when it comes to interacting with young children?) and their learning experiences (e.g., In what context did you learn most with respect to interaction skills: at school, in the work placement, or the combination of both?). At each wave, a number of key questions related to interaction skills was similar; additional questions were added at different waves (e.g., reflecting on one's personal growth during the pre-service training in the final interview). In total, 125 interviews were gathered in a 3 years period.

\section{Questionnaire}

Demographic characteristics of the pre-service teachers were gathered in the first year with a brief questionnaire, including country of birth, native language, and age.

\section{Procedure}

The participants were informed about the study by their teacher educators in the beginning of the first school year. The teachers also indicated that each pre-service teacher was allowed to participate or not, and participation in the study was based on each students' individual decision; students were also informed they could stop participating in the longitudinal study. After receiving informed consent, the research team made appointments with the coordinating teacher educator, the pre-service teacher and the center director of the work placement group. The parents at each center were informed about the goal of the study and the research procedures, and they could indicate whether their child was allowed to be video-recorded or not.

A trained research assistant visited the pre-service teachers in their work placement groups in child care settings. Second, the assistant interviewed each participant individually in a separate room with an interview guide. At the beginning of the first interview, the research assistant explained the study procedures once again and also enquired about possible questions of the pre-service teachers related to the study procedures. The interviews were recorded using an audio-recorder and transcribed for analysis. After the interviews, following a standardized protocol for our validated measure, the assistant made video recordings of the pre-service teachers in interaction with the children, in two situations; during lunch/snack-time and during structured play. The play materials changed at each measurement moment during the structured observations to reduce any instrumentation effect; the general procedure and instruction remained unchanged.

\section{Analysis}

We analyzed all longitudinal quantitative CIP data with a multilevel growth model to take into account the hierarchical data structure with repeated measures nested under individual teachers; this technique also allowed us to analyze all available data. The professional growth is expressed as increase per academic year, measured from the start of the course. The fit of the unconditional means model, $\chi^{2}(2)=312.5$, improved significantly to $\chi^{2}(5)=287.2$ after adding random intercepts and random slopes, $\Delta \chi^{2}(3)=25.3$, $p<.001$. The random part was fitted with an unstructured covariance model. In an explorative analysis, predictors at teacher level were finally added to this basic model in order to explain significant variation in outcomes.

All interviews were recorded, transcribed, and analysed with the MAXQDA software program. At first, we developed a deductive coding scheme with curriculum-based codes for the six interaction skills. Subsequently, inductive codes were added. In this way we could identify and summarise all relevant data from the interviews. The final coding scheme comprised six main codes and 118 sub-codes. In total, 125 interviews were included with 7584 coded segments. These coded segments consisted of words, sentences or paragraphs containing a shared theme. Three research assistants individually coded the transcripts. To check interrater agreement, a random sample of the transcripts was double coded ( $N=292$, approximately $4 \%$ of all 7584 segments) with the coding scheme. The interrater reliability for each main varied between .80 and .97 with a mean of .87 . We selected interview codes related to the development of interaction skills to investigate the perspectives of pre-service teachers related to the PD of their interaction skills. We explored, for each distinguished skill, whether there were important developments in the interview data from wave 1-4 that would contextualise the quantitative results, such as problems related to the use of the skills in practice. Further, we aimed to integrate findings from the qualitative interview data related to their PD on interaction skills and the quantitative growth of these skills during pre-service training by quantifying the results from the interview into a variable called level of reflection.

\section{Results}

\section{Pre-service Teachers' Growth of Interaction Skills}

The CIP level of the pre-service teachers displayed steady growth during the entire course (see Fig. 1). The longitudinal analysis showed a statistically significant positive, linear trend $(p<.001)$. The linear growth for the CIP total score was 0.42 points per year. This growth was significant 
Fig. 1 Proportion of pre-service teachers' interviews: inclusion of coded interview segments concerning different interaction skills

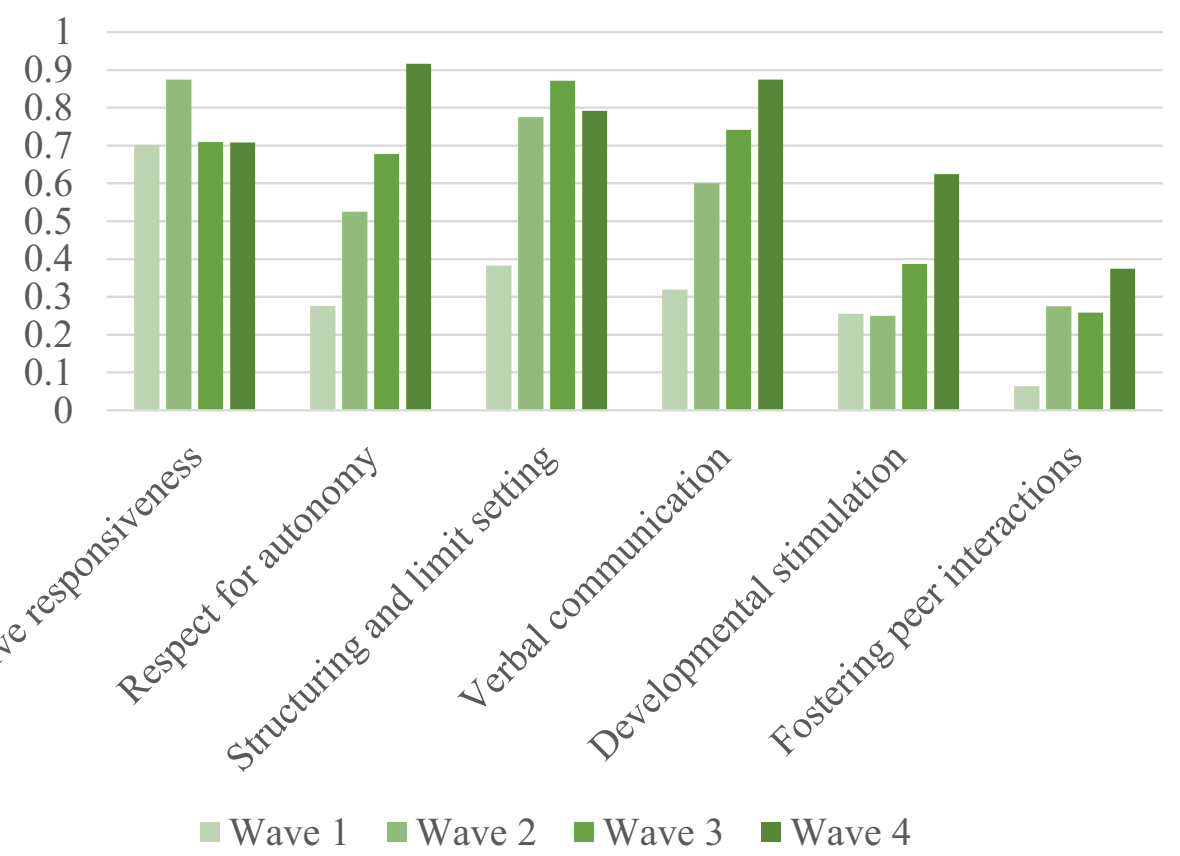

in comparison to the starting level as from the second year, $p<.001$, and from the second to the third year as well, $p=.004$. The growth from the beginning up to and including the fourth measurement and final year of the course was substantial with a very large effect size $(d=1.67)$. The growth for individual interaction skills varied from 0.32 to 0.54 points per year on a seven-points scale with substantial effect sizes for all distinguished skills, ranging from 0.99 for developmental stimulation to 1.29 for sensitive responsivity.

The total CIP score, which on average was inadequate at the start of the course, was adequate to good by the end of the course. The individual interaction skills showed a comparable picture. The average level of the interaction skills was adequate at the beginning of the study for only one skill, namely sensitive responsivity. By the end of the course, the average level was adequate for three skills: sensitive responsivity, respect for autonomy, and structuring and limit setting. The score for verbal communication fell between inadequate and good. The average level remained inadequate for developmental stimulation and facilitating positive peer interactions, although pre-service teachers showed growth for these outcome measures as well.

\section{Perspectives of Pre-service Teachers on Their Professional Development}

The interviews revealed typical challenges the pre-service teachers faced with learning each different interaction skill. They frequently addressed topics related to sensitive responsivity, respect for autonomy and structuring and limit setting as basic interaction skills. For sensitive responsivity, they indicated in the interviews they had to strike a balance between individual children and the group (e.g., 'I think I learned to better divide my attention over kids. So, not to focus constantly on only one or two children, but on the whole group', teacher N, wave 1). One of the teachers indicated that she learned to act more friendly to the children, which shows that not all students have obtained elementary skills at the start of pre-service education ('I was easily irritated in my reaction to children. I started screaming for instance, or gave them a really snappy response. Then I got pointed out that I had to speak to them more calmly, and to say things in a different way', teacher S, wave 2). Related to respect for autonomy, pre-service teachers also indicated that they had learned how to adjust their pace and to become more patient with children's routines. Furthermore, they posited that they had learned not to take over children's activities and to give room to the children's initiatives ('For instance, when we go outside and they are putting on their coats, you just want to quickly put on that jacket and go outside. But actually, you have to let them put on their own jackets, so they can learn to do that themselves', teacher $\mathrm{E}$, wave 1). A salient finding in the interviews related to structure and limit setting, was that the participants found it difficult to organise the classroom and to intervene and set limits when necessary ('Now I take more initiatives, I dare to do more things with the children. Because, at first, I was a bit shy. Now I dare to say to the kids what is allowed and what is not', teacher R, wave 2; 'At first, I did not dare to approach the children when they did something wrong, I was scared to do something wrong. Now I feel that I made progress in doing that', teacher $\mathrm{M}$, wave 2). 
The skills verbal communication, developmental stimulation and fostering positive peer interactions relate to educational skills and instructional support. The pre-service teachers grappled with different learner's issues with verbal communication. Some of the teachers learned during their pre-service training that they could articulate their plans and acts to make clear for the children what they were doing. In the words of one of the teachers: 'I used to think that when we're at the table, children have to eat without talking. But I don't have to be that way. They can talk, you can also have a little chat while eating fruit, and I did not do that', teacher $\mathrm{V}$, wave 3). Furthermore, the pre-service teachers indicated in the interviews that they were involved in various group activities, but their comments did not reveal a clear agenda for developmental stimulation (e.g., 'You can let them build towers with these blocks, but you can also talk about the different colours and shapes of the blocks. So you can also talk, instead of just focussing on building a tower', teacher S, wave 4). Finally, fostering positive peer interactions proved to be a rare topic in the interviews. The few quotes related to this topic illustrated that some of the trainees recognised this skill and also acknowledged its importance. One of the participants indicated, for example, that children should not 'isolate themselves from the group' and should 'play together' ('Especially fostering peer interactions, when children are playing together, is very important (...) Providing a mixed group and preventing that children are isolating themselves from the group', teacher M, wave 4). Another teacher suggested as a concrete strategy to let 'children sit next to each other'. However, fostering positive peer interactions was not an explicit topic in the interviews and most trainees did not mention concrete strategies for this skill.

\section{Pre-service Teachers' Level of Reflection}

The interviews showed that the proportion of pre-service teachers who mentioned one or more of the six interaction skills increased during the study for most skills (see Fig. 2). Figure 2 also shows that developmental stimulation and fostering positive peer interactions were less frequently mentioned in the interviews.

Focusing on codes from the interviews that were related to the development of the interaction skills, participants appeared to reflect more often on the first three, more basic interaction skills in their first academic year. Sensitive responsiveness, respect for autonomy and structuring and limit setting were mentioned most often in the second round of interviews. Self-reported growth in verbal communication was mentioned most often in year 2 (wave 3) and, finally, growth on developmental stimulation was most frequent in their final year (wave 4). Self-reported growth on fostering positive peer interactions was barely mentioned by the participants at all. The qualitative analysis showed a clear progress from more reflection related to basic interaction skills to reflecting on educational skills. Developmental stimulation and fostering positive peer interactions appeared as only minor topics in the interviews; this latter finding was also in line with the relatively low scores for these interaction skills in the observations.

The interviews revealed different levels of reflection on one's development of interaction skills in ECEC. This level of reflection in the interviews was related to the level of the interaction skills from the observations: the number of coded segments related to interaction skills in the interviews was associated with students' total CIP scores on the basis of the video observations, $r=.24, p=.01$.
Fig. 2 Development of interaction skills during pre-service training: CIP scores at Wave 1 , 2, 3 and 4

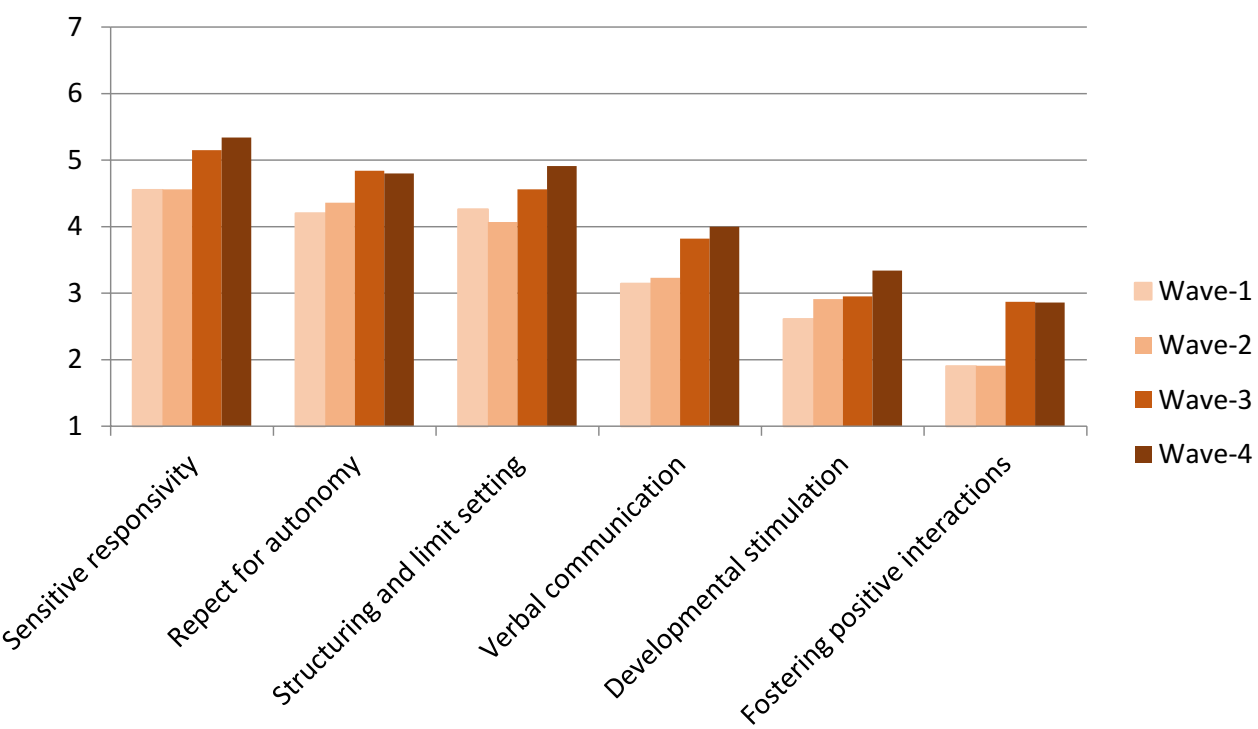


Table 1 Results of multilevel analysis for the growth of interactive skills

\begin{tabular}{|c|c|c|c|c|c|c|c|c|}
\hline & & CIP-total & SR & RA & SL & $\mathrm{VC}$ & DS & FPI \\
\hline \multicolumn{9}{|l|}{ Fixed effect } \\
\hline & Intercept & $2.87 * * *$ & $3.92 * * *$ & $3.94 * * *$ & $3.98 * * *$ & $2.55^{* * *}$ & $2.34 * * *$ & $1.39 * * *$ \\
\hline & Practice-based learning & $0.34 * *$ & $0.42 * *$ & - & - & $0.43 *$ & - & $0.56 * * *$ \\
\hline & Native language NL & $0.39 * *$ & - & $0.35 *$ & - & $0.47 *$ & $0.43 *$ & - \\
\hline Time (years) & & $0.42 * * *$ & $0.40 * * *$ & $0.34 * * *$ & $0.35^{* *}$ & $0.47 * * *$ & $0.32 * *$ & $0.54 * * *$ \\
\hline \multicolumn{9}{|l|}{ Random effect } \\
\hline Level 1 & Individual & $0.23 * * *$ & $0.61 * * *$ & $0.42 * * *$ & $0.59 * * *$ & $0.39 * * *$ & $0.49 * * *$ & $0.65 * * *$ \\
\hline \multirow[t]{3}{*}{ Level 2} & Intercept & 0.18 & & 0.23 & $0.62 *$ & $0.45^{*}$ & 0.21 & \\
\hline & Growth & 0.06 & $.00^{\mathrm{a}}$ & 0.04 & 0.06 & 0.12 & 0.06 & $.02^{\mathrm{a}}$ \\
\hline & Covariance & -0.07 & & -0.06 & -0.17 & -0.17 & -0.05 & \\
\hline \multirow[t]{3}{*}{ Start model } & Deviation & 261.2 & 356.4 & 324.7 & 380.4 & 347.3 & 347.8 & 368.7 \\
\hline & AIC & 273.2 & 368.4 & 336.7 & 392.4 & 359.3 & 359.8 & 380.7 \\
\hline & BIC & 291.0 & 386.2 & 354.4 & 410.1 & 377.1 & 377.5 & 398.4 \\
\hline \multirow[t]{3}{*}{ Final model } & Deviation & 247.1 & 336.5 & 320.2 & 380.4 & 337.1 & 342.4 & 355.9 \\
\hline & AIC & 246.2 & 348.5 & 334.2 & 392.4 & 353.1 & 356.4 & 356.9 \\
\hline & BIC & 286.8 & 366.2 & 354.9 & 410.1 & 376.8 & 377.1 & 380.7 \\
\hline $\mathrm{R}^{2}$ & & .71 & .29 & .58 & .62 & .74 & .58 & .41 \\
\hline
\end{tabular}

$S R$ sensitive responsivity; $R A$ respect for autonomy; $S L$ structuring and limit setting; $V C$ verbal communication; $D S$ developmental stimulation; FPI fostering positive peer interactions

p-values: $*<.05 ; * *<.01 ; * * *<.001$

${ }^{a}$ An identity model with one random parameter was estimated for SR and FPI; Start model is the unconditional growth model without predictors; $R^{2}$ is the correlation between predicted and observed values.

\section{Predictors of Pre-service Teachers' Interaction Skills}

An explorative analysis revealed two predictors for the development of interaction skills (see Table 1). The participants in the on-the-job track had higher scores for the CIP, sensitive responsivity, verbal communication, and fostering positive peer interactions. Further, the total score of students whose native language was Dutch showed greater growth during pre-service training for respect for autonomy, verbal communication, and developmental stimulation (see Table 1); the significant predictors on-the-job pathway and the native language were not related $(C C=.03, p=.82)$. The effect of the on-the-job pathway and Dutch as native language were individually as large as the growth that was visible after one academic year. Other predictors (training level three or four, age, having children) and interaction effects of the time factor with the statistically significant background characteristics of the students (i.e., learning pathway or native language) proved to be not significant.

\section{Discussion}

The results of this small-scale, longitudinal study give insight in the development of the interaction skills of preservice teachers from the very beginning of their preservice teacher education until the end. The qualitative interview data suggest that pre-service teachers' reflection on their interaction skills starts with basic interaction skills related to emotional support in the first year and shifts towards instructional support in the second and third year of their education. Furthermore, the pre-service teachers showed an impressive development of their interaction skills after 3 years of pre-service education. Scientific research has shown that not all pre- or in-service interventions for ECEC staff are (equally) effective (Egerrt et al. 2018; Fukkink and Lont 2007). This effect from our study into the PD during pre-service training is considerably larger, compared to the effect of in-service training on interaction skills of ECEC teachers, as reported by Fukkink and Lont $(2007, E S=0.45)$ and Werner et al. (2016, ES =0.45). The outcomes of this study thus underscore the importance of pre-service training for the development of interaction skills and the level of professional reflection for ECEC teachers. Our study also shows, despite the significant overall growth, a clear difference in performance level between emotional support and instructional support. Related to this, developmental stimulation and fostering positive peer interactions were relatively infrequent in the interviews at all stages of the pre-service education, and these skills seem, therefore, not high on the agenda, possibly explaining the relatively low levels in the instructional domain. 
The divide between emotional support and class management on the one hand, and instructional support on the other hand, has also repeatedly been found for qualified ECEC teachers (see Guo et al. 2010; Hamre 2014; Helmerhorst et al. 2015). Developmental stimulation, therefore, emerges as an obviously weaker and often insufficient element of the process of quality early childhood education. It seems, therefore, that regular training approaches do not seem to produce satisfying results yet for instructional support, and additional efforts seem required in development and training.

Findings from this study suggest that pre-service teachers are aware of the importance of emotional support and also focus on verbal communication in a later stage of their training, whereas instructional skills was less prominent in the interview. Possibly, the Dutch 3 year pre-service teacher training is too brief to cover the wide spectrum of interaction skills, which play an important role in fostering the well-being and development of young children. It may also be possible that higher levels of instructional support may require specific tracks in pre-service training devoted to the design and delivery of high-quality instructional support in ECEC.

\section{Limitations and Suggestions for Future Research}

A first limitation of this research is the relatively small sample that was recruited via the Regional Training Centre of Amsterdam. The attrition of students, which is characteristic of both longitudinal studies and Dutch preservice teacher education, reduced the sample.

Second, the effect of training of the distinguished interaction skills from this study, was found in a national context with uniform preservice teacher education requirements and a national training profile that is deduced from a professional profile. The distinguished interaction skills from the Caregiver Interaction Profile have recently been included in national professional handbooks and are also incorporated in the Dutch standards for the curriculum for early childhood education. This match between the national professional profile and the pre-service curriculum may have contributed to the generally high levels of PD in key interaction skills. A match between training requirements and the professional profile exists in other European countries such as Belgium, Finland, France, Germany, Spain, and England (see Urban et al. 2012), but is not found in all countries. Generalisation of the results to the preservice teacher education programs in other countries may therefore not be self-evident.

Finally, another limitation is directly related to the longitudinal design. Although only this type of research can identify development over time, the observed growth of the students obviously cannot be attributed solely to their training, but may also be influenced by maturation and possible instrumentation effects.

\section{Implications for Teacher Education}

As far as we are aware, this study is the first longitudinal research into the development of interaction skills among pre-service ECEC teachers. The outcomes of our mixedmethods study suggest that pre-service teachers take a major step forwards in the renewed Dutch pre-service training with interaction skills and professional reflection on their interaction with young children, which provides evidence for the effectiveness of early childhood teacher education in this domain. However, a larger sample is needed to generalize findings to a wider population of regional centers and a wider population of preservice ECEC teachers.

This study also suggests, with previous studies of quality assessment in ECEC practice, that additional investments are needed to achieve higher levels of instructional support in ECEC practice. Studies also show that qualified ECEC teachers appear to be relatively proficient in offering emotional support, but markedly weaker when it comes to instructional support, including studies from various countries, like Estonia and Finland (Lerkkanen et al. 2012), Germany (von Suchodoletz et al. 2014) and the United States (e.g., Denny et al. 2012). The findings from our study suggest that relatively extensive training may be required to improve the instructional skills of ECEC teachers after they have completed their teacher education program. However, it is vital to invest in instructional skills during preservice training. Given the key role of the ECEC teacher for highquality effectiveness in the instructional domain, future studies should explore which training approaches are successful in elevating the levels of instructional support for pre-service and in-service teachers.

Funding This study was funded by Bureau Kwaliteit Kinderopvang (BKK) (Grant No. BKK001).

\section{Compliance with Ethical Standards}

Conflict of interest The authors report no conflicts of interest.

Open Access This article is distributed under the terms of the Creative Commons Attribution 4.0 International License (http://creativeco mmons.org/licenses/by/4.0/), which permits unrestricted use, distribution, and reproduction in any medium, provided you give appropriate credit to the original author(s) and the source, provide a link to the Creative Commons license, and indicate if changes were made.

\section{References}

Creswell, J. W., Plano Clark, V. L., Gutmann, M. L., Hanson, W. E. (2003). Advanced mixed methods research designs. In A. M. Tashakkori, \& C. B. Teddlie (Eds.), Handbook of mixed methods in social and behavorial research (pp. 209-240). Thousand Oakes: Sage. 
Denny, J. H., Hallam, R., \& Homer, K. (2012). A multi-instrument examination of preschool classroom quality and the relationship between program, classroom, and teacher characteristics. Early Education and Development, 23(5), 678-696. https://doi. org/10.1080/10409289.2011.588041.

Egert, F., Fukkink, R., \& Eckhardt, A. G. (2018). Impact of in-service professional development programs for early childhood teachers on quality ratings and child outcomes: A meta-analysis. Review of Educational Research, 88(3), 401-433. https://doi. org/10.3102/0034654317751918.

Eurydice (2014). Key data on early childhood education and care in Europe. Retrieved from http://eacea.ec.europa.eu/education/euryd ice/documents/key_data_series/166EN.pdf.

Faul, F., Erdfelder, E., Lang, A.-G., \& Buchner, A. (2007). G*Power 3: A flexible statistical power analysis program for the social, behavioral, and biomedical sciences. Behavior Research Methods, 39, 175-191. https://doi.org/10.3758/BF03193146.

Fukkink, R. (2018). The Netherlands-ECEC Workforce Profile. In P. Oberhuemer, \& I. Schreyer (Eds.), Early Childhood Workforce Profiles in 30 Countries with Key Contextual Data. Munich: Deutsches Jugendinstitut.

Fukkink, R. G., \& Lont, T. A. E. (2007). Does training matter? A metaanalysis and review of experimental studies of caregiver training. Early Childhood Research Quarterly, 22(3), 294-311. https://doi. org/10.1016/j.ecresq.2007.04.005.

Guo, Y., Piasta, S. B., Justice, L. M., \& Kaderavek, J. N. (2010). Relations among preschool teachers' self-efficacy, classroom quality, and children's language and literacy gains. Teaching and Teacher Education, 26, 1094-1103. https://doi.org/10.1016/j. tate.2009.11.005.

Hamre, B. K. (2014). Teachers' daily interactions with children; An essential ingredient in effective early childhood programs. Child Development Perspectives, 8(4), 223-230. https://doi.org/10.1111/ cdep.12090.

Helmerhorst, K. O. W., Riksen-Walraven, J. M., Fukkink, R. G., Tavecchio, L. W. C., \& Gevers Deynoot-Schaub, M. J. J. M. (2017). Effects of the caregiver interaction profile training on caregiverchild interactions in child care centers. Child \& Youth Care Forum, 46, 413-436. https://doi.org/10.1007/s10566-016-9383-9.

Helmerhorst, K. O. W., Riksen-Walraven, J. M., Gevers deynootSchaub, M. J. J. M., Fukkink, R. G., \& Tavecchio, L. W. C. (2015). Child care quality in the Netherlands over the years: A closer look. Early Education and Development, 26, 89-105. https://doi. org/10.1080/10409289.2014.948784.

Helmerhorst, K. O. W., Riksen-Walraven, J. M. A., Vermeer, H. J., Fukkink, R. G., \& Tavecchio, L. W. C. (2014). Measuring interactive skills of caregivers in child care centers: Development and validation of the caregiver interaction profile scales. Early Education and Development, 25(5), 770-790. https://doi.org/10.1080/10409 289.2014.840482.

Institute of Medicine and National Research Council. (2015). Transforming the workforce for children birth through age 8: A unifying foundation. Washington, DC: The National Academies Press.

Lerkkanen, M. K., Kikas, E., Pakarinen, E., Trossman, K., Poikkeus, A. M., Rasku-Puttonen, H., Siekkinen, M., Nurmi, J. E. (2012). A validation of the early childhood classroom observation measure in Finnish and Estonian kindergartens. Early Education \& Development, 23(3), 323-350. https://doi.org/10.1080/10409 289.2010.527222.
MAXQDA 11-Software for Qualitative Data Analysis 1989-2016. Berlin, Germany: VERBI.

Mischo, C. (2015). Early childhood teachers' perceived competence during transition from teacher education to work: Results from a longitudinal study. Professional Development in Education, 41, 75-95. https://doi.org/10.1080/19415257.2014.886282.

NAEYC (2009). Standards for Early Childhood Professional Preparation. Retrieved from https://www.naeyc.org.

Oberhuemer, P., \& Schreyer, I. (Eds.). (2018). Early Childhood Workforce Profiles in 30 Countries with Key Contextual Data. Munich: Deutsches Jugendinstitut. Retrieved from https://www.seepro.eu.

Schachter, R. E. (2015). An analytic study of the professional development research in early childhood education. Early Education and Development, 26, 1057-1085. https://doi.org/10.1080/10409 289.2015.1009335.

Sheridan, S. M., Edwards, C. P., Marvin, C. A., \& Knoche, L. L. (2009). Professional development in early childhood programs: Process issues and research needs. Early Education and Development, 20, 377-401. https://doi.org/10.1080/10409280802582795.

Snyder, P., Hemmeter, M. L., Meeker, K. A., Kinder, K., Pasia, C., \& McLaughlin, T. (2012). Characterizing key features of the early childhood professional development literature. Infants and Young Children, 25(3), 188-212. https://doi.org/10.1097/YC.0b013 e31825a1ebf.

Spybrook, J., Raudenbush, S. W., Congdon, R., \& Martinez, A. (2011). Optimal design for longitudinal and multilevel research: Documentation for the Optimal Design Software V.3.0. Retrieved from http://hlmsoft.net/od/.

Strohmer, J., \& Mischo, C. (2016). Does early childhood teacher education foster professional competencies? Professional competencies of beginners and graduates in different education tracks in Germany. Early Child Development and Care, 186, 42-60. https ://doi.org/10.1080/03004430.2014.985217.

Sumrall, T. C., Scott-Little, C., La Paro, K. M., Pianta, R. C., Burchinal, M, Hamre, B., Downer, J., \& Howes, C. (2017). Student teaching within early childhood teacher preparation programs: An examination of key features across 2- and 4-year institutions. Early Childhood Education Journal, 45, 821-830. https://doi. org/10.1007/s10643-016-0830-x.

Urban, M., Vandenbroeck, M., Van Laere, K., Lazzari, A., \& Peeters, J. (2012). Towards competent systems in early childhood education and care; Implications for policy and practice. European Journal of Education, 47, 508-526. https://doi.org/10.1111/ejed.12010.

Vartuli, S., \& Rohs, S. (2009). Early childhood prospective teacher pedagogical belief shifts over time. Journal of Early Childhood Teacher Education, 30, 310-327.

Von Suchodoletz, A., Faesche, A., Gunzenhauser, C., \& Hamre, B. K. (2014). A typical morning in preschool: Observations of teacher-child interactions in German preschools. Early Childhood Research Quarterly, 29(4), 509-519. https://doi.org/10.1016/j. ecresq.2014.05.010.

Werner, C. D., Linting, M., Vermeer, H. J., \& Van IJzendoorn, M. H. (2016). Do intervention programs in child care promote the quality of teacher-child interactions? A meta-analysis of randomized controlled trials. Prevention Science, 17, 259-273. https://doi. org/10.1007/s11121-015-0602-7. 